\title{
Pharmacognostic and Pharmacological Evaluation of Hyssopus officinalis L. (Lamiaceae) Collected from Kashmir Himalayas, India
}

\author{
Akanksha Srivastava, Kuldeep Awasthi, Bhanu Kumar, Ankita Misra, Sharad Srivastava*
}

\section{Akanksha Srivastava, Kuldeep Awasthi, Bhanu Kumar, Ankita Misra, Sharad Srivastava*}

Pharmacognosy and Ethnopharmacology Division CSIR-National Botanical Research Institute, Lucknow, Uttar Pradesh, INDIA.

\section{Correspondence}

Dr. Sharad Srivastava

Pharmacognosy and Ethnopharmacology Division CSIR-National Botanical Research Institute, Lucknow, Uttar Pradesh, INDIA.

Phone No: 91-522-2297818, Fax: 91-522-2205836

E-mail: sharad_ks2003@yahoo.com

History

- Submission Date: 15-01-2018;

- Review completed: 05-03-2018;

- Accepted Date: 03-05-2018

DOI : 10.5530/pj.2018.4.114

Article Available online

http://www.phcogj.com/v10/i4

\section{Copyright}

(C) 2018 Phcog.Net. This is an openaccess article distributed under the terms of the Creative Commons Attribution 4.0 International license.

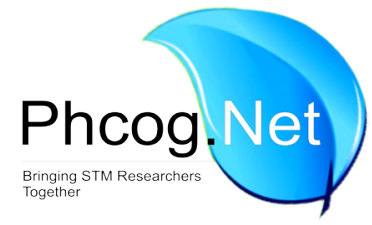

ABSTRACT

Introduction: Hyssopus officinalis L. is a well-known herb for its culinary and medicinal significance. The purpose of this study was to perform the pharmacognostic evaluation. Methods: Physicochemical and phytochemical analysis, HPTLC quantification and in vitro antioxidant and antidiabetic activity were done. Results: Preliminary screening revealed the presence of phytomolecules such as alkaloid $(0.99 \%)$, tannin $(1.75 \%)$, sugar $(1.96 \%)$ and starch $(0.68 \%)$. Total phenolic and flavonoid content were found to be $2.32 \%$ and $1.16 \%$ respectively. HPTLC quantification data showed that the content of ferulic acid $(0.034 \%)$ was higher than caffeic acid $(0.0064 \%)$ on dry weight basis The $\mathrm{IC}_{50}$ value for the in vitro $\mathrm{DPPH}$ radical scavenging assay was $0.50 \mu \mathrm{g} / \mathrm{ml}$ and in vitro anti diabetic assay displayed $I C_{50}$ value of $0.8366 \mathrm{mg} / \mathrm{ml}$. Conclusion: The study suggests presence of considerable amount of phenolic acids and antioxidant activity in the plant which supports its use in the traditional systems of medicine. Key words: Antioxidant, DPPH, Hyssopus officinalis, HPTLC, Phenolic acids.

\section{INTRODUCTION}

Hyssop (Hyssopus officinalis L., family: Lamiaceae) is a native of South European countries. In India, it is found in the Western Himalayan region from Kashmir to Kumaun at altitudes of 8,000-11,000 ft. ${ }^{1}$ In its natural habitat it grows on dry banks, among rocks and ruins with a height ranging from 50 to $120 \mathrm{~cm}$. The genus Hyssopus comprises of aromatic perennial herbs or sub-shrubs known for their culinary as well as medicinal properties for hundreds of years and the leaves are mainly used as an aromatic condiment. Hyssop oil from aerial part finds its greatest use in flavoring preparations for alcoholic beverages, meat products and seasonings. ${ }^{2}$ Medicinally, it is used as an expectorant, carminative, anti-inflammatory, anti catarrhal, antispasmodic and as traditional medicine in many parts of the world. The herb was used to alleviate digestive disorders, cure laryngitis and to accelerate wound healing in Turkish folk medicine, relaxation of peripheral blood vessels and to promote sweating., ${ }^{3,45}$ It is used in tea blends for cough relief, antispasmodic effects and relieving catarrh. Apart from this, H. officinalis exhibit various other pharmacological activities i.e. anti-bacterial, anti-fungal, anti-oxidant, sedative, spasmolytic, anti-viral, cytotoxic and anti platelet activities of Hyssop extract have been also reported. ${ }^{6,7}$ Several studies have reported the composition of essential oil isolated from $H$. officinalis, the major constituents were found to be pino-camphone, iso-pinocamphone, $\beta$-pinene, 1, 8-cineole and pino-carvone. ${ }^{8}$ Antibacterial, antifungal and antioxidant properties of hyssop have been attributed to the presence of pinocamphone, iso-pinocamphone and $\beta$-pinene. Antiviral activity has probably been attributed to the presence of caffeic acid and tannins. ${ }^{9,10}$ As evident from available literature that majority of work was focused on chemical characterization of $H$. officinalis oil. Hence, this study aimed for physicochemical standardization of H. officinalis aerial part. In addition, the phenolics were quantified through HPTLC and their bioactivity was analyzed by different models. This aids in quality regulation of raw material for more pronounced culinary use as well as this also promotes the cultivation of species in its natural location.

\section{MATERIALS AND METHODS}

\section{Plant material}

The aerial part of $H$. officinalis used in the present study was collected from Kashmir-Leh highway (India) in the month of October 2016 at an altitude of $11,562 \mathrm{ft}$. The plant was found in flowering condition. The collected germplasm was authenticated by Dr. Sharad Srivastava, principal scientist, CSIRNBRI, Lucknow. A voucher number was assigned (LWG No 262569) and the herbarium specimen was deposited in the national repository of CSIRNational Botanical Research Institute, Lucknow.

Cite this article: Srivastava A, Awasthi K, Kumar B, Misra A, Srivastava S. Pharmacognostic and Pharmacological Evaluation of Hyssopus officinalis L. (Lamiaceae) Collected from Kashmir Himalayas, INDIA. Pharmacog J. 2018;10(4):690-3. 


\section{Physicochemical and phytochemical characterization}

Physicochemical and phytochemical studies viz. extractive values, total ash, acid insoluble ash, total sugar, starch, tannin and phenols were estimated from shade-dried and powdered plant material were also carried out. ${ }^{11,12,13}$

\section{HPTLC quantification}

\section{Preparation of plant extract}

Accurately weighed $5 \mathrm{~g}$ of powdered sample was cold macerated with absolute methanol $(25 \mathrm{ml})$, kept on shaker for $08 \mathrm{hrs}$ and allowed to stay for $16 \mathrm{hrs}$ at room temperature $\left(25 \pm 2^{\circ} \mathrm{C}\right)$. Extraction was repeated thrice, filtered (Whatman No. 4) and pooled filtrate was dried in rotatory evaporator (Buchi, USA) under standard conditions of temperature $\left(45 \pm 2^{\circ} \mathrm{C}\right.$ ) and pressure (40 mbar) and finally lyophilized (Labconco, USA) to solid residue. Before extraction, the sample was defatted using petroleum ether to remove the fatty materials/impurity. Extractive yield (\%) was calculated on dry weight basis.

\section{Instrumentation and chromatographic conditions}

HPTLC, quantification of phenolics were carried out on silica gel G60 $\mathrm{F}_{254}$ precoated aluminum plate with $0.2 \mathrm{~mm}$ thickness (Merck, Germany) as stationary phase. Prior to HPTLC profiling, the stock solution of marker compounds and plant sample was freshly diluted with methanol and filtered through a $0.45 \mu \mathrm{m}$ Millipore membrane filter (pall, USA) to prepare working solution of $0.1 \mathrm{mg} / \mathrm{ml}$ and $10 \mathrm{mg} / \mathrm{ml}$ respectively. Working solutions of plant sample $(15 \mu \mathrm{l})$ and marker compounds viz. ferulic acid and caffeic acid $(2 \mu \mathrm{l})$ were applied on plate as $6 \mathrm{~mm}$ wide bands positioned $10 \mathrm{~mm}$ above the bottom and $15 \mathrm{~mm}$ from the side of the plate, using CAMAG Linomat V automated TLC applicator (the nitrogen flow providing a delivery speed of $150 \mathrm{nl} \mathrm{s}^{-1)}$ from the application syringe. The chromatogram was developed with mobile phase of Toluene: Ethyl acetate: Formic acid $(6: 3: 1, \mathrm{v} / \mathrm{v} / \mathrm{v})$ in CAMAG twin through chamber. After development, plates were dried for $30 \mathrm{~min}$ and scanning was performed using CAMAG TLC Scanner 3 at wavelength of $300 \mathrm{~nm}$, operated by win CATS Software (version 3.2.1). The slit dimensions were $4 \times 0.45 \mathrm{~mm}$ and the scanning speed was $100 \mathrm{~mm} / \mathrm{s}$. Quantification (\% dry weight basis) was done based on regression analysis of area versus concentration of marker compounds dilutions. ${ }^{14}$

\section{Antioxidant activity}

The antioxidant potential of methanolic extract was evaluated by three methods viz. DPPH radical scavenging assay, ${ }^{15}$ reducing power assay ${ }^{16}$ and total anti-oxidant capacity ${ }^{17}$ to estimate the hydroxyl radical scavenging activity of $H$. officinalis.

\section{Antidiabetic activity}

The antidiabetic assay was performed based on the alpha amylase inhibition assay with slight modification based on the starch-iodine test. ${ }^{18}$

\section{RESULTS}

\section{Physicochemical standardization}

Physicochemical standardization parameters were carried out as per standard protocols of Ayurvedic Pharmacopoeia of India (1989) to furnish data that can be used as quality regulation for herbal product development. The ash values viz. acid insoluble ash, water insoluble ash was found to be $12.40 \%$, and $10.98 \%$ respectively. Alcohol extractive (\%) was $1 \%$ and hexane extractive was $2.65 \%$. However, the water extractive was found to be significantly high i.e. $15 \%$ in the plant (Figure 1).

\section{Quantitative estimation of secondary metabolites}

The phytochemical screening (qualitative) of $H$. officinalis leaf extract shows presence of various bioactive compounds like alkaloid, carbohydrate, tannin, flavonoid, sterols and terpenoids. Sugar and starch content were

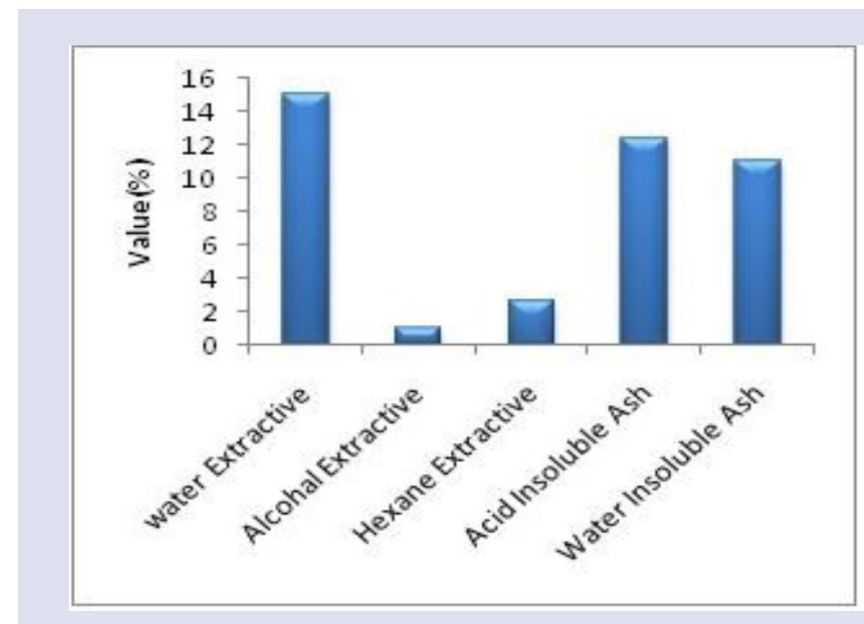

Figure 1: Physicochemical values of $H$. officinalis.

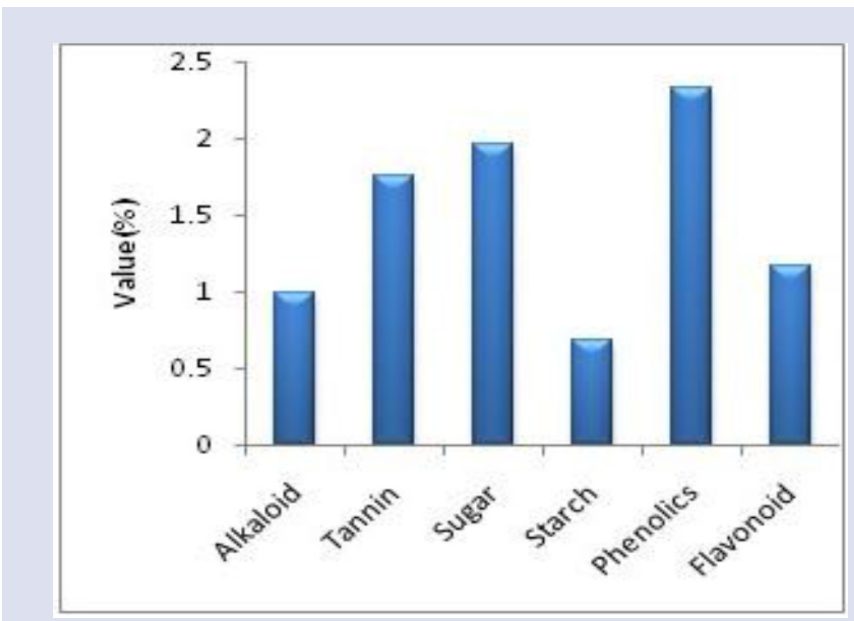

Figure 2: Phytochemical evaluation of $H$. officinalis.

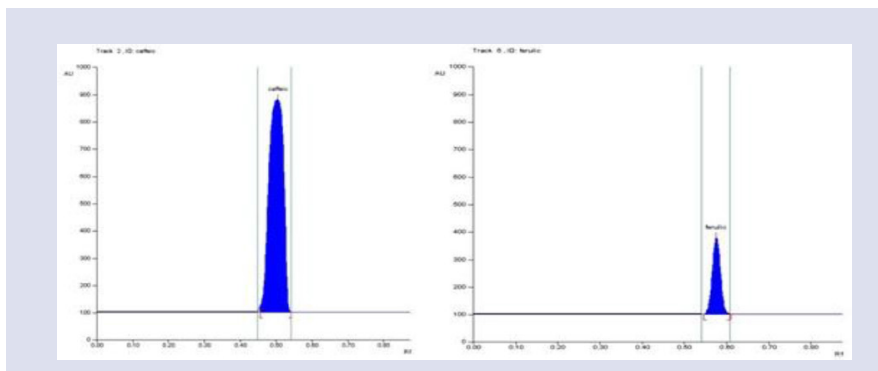

Figure 3: HPTLC denistometric scan profile of ferulic and caffeic acid showing distinct $R_{f}$ values.

found to be $1.96 \%$ and $0.68 \%$. Total phenolic content was found to be higher than flavonoid contents in the methanolic extract. Tannin content was recorded as $1.75 \%$ and alkaloid content was $0.99 \%$ (Figure 2). The results indicate that the plant is rich in various phytomolecules.

\section{High performance thin layer chromatography}

The method for quantification of phenolic was previously developed. HPTLC profile of methanolic extract of $H$. officinalis was done by CAMAG HPTLC System with winCATS-3 software. The marker 


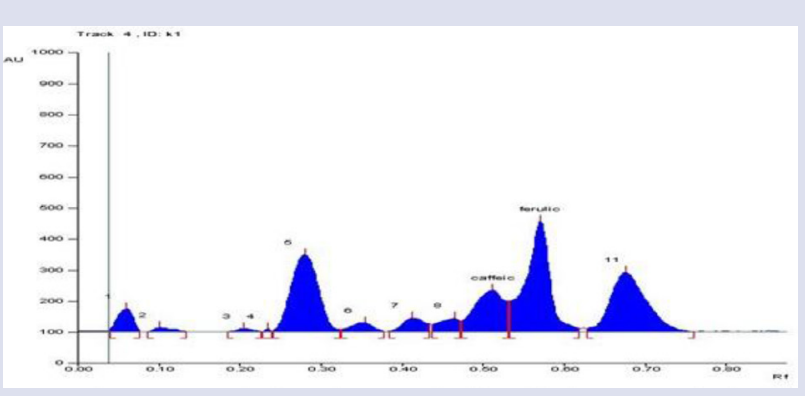

Figure 4: HPTLC densitometric scan profile of $H$.officinalis $L$. extract showing presence of ferulic and caffeic acid.

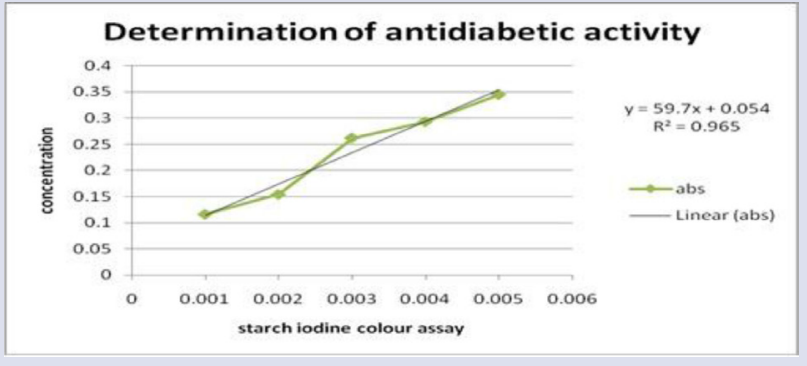

Figure 5: In vitro antidiabetic activity of $H$. officinalis extract by a-amylase inhibition methods

compounds were identified by matching the UV spectra and $\mathrm{R}_{\mathrm{f}}$ of bands in the plant sample with marker compounds (Figure 3). The densiometric scanning reveals the presence of caffeic acid and ferulic acid in the crude extract at $\mathrm{R}_{\mathrm{f}}$ of 0.50 and 0.57 respectively (Figure 4 ). The content of ferulic acid $(0.034 \%)$ was higher than caffeic acid $(0.0064 \%)$ on dry weight basis in crude drug.

\section{Antioxidant activity}

The antioxidant potential of the plant extract was determined by the total antioxidant capacity, reducing power assay, and DPPH radical scavenging assay. The total antioxidant capacity of $H$. officinalis extract was measured by phospho-molybdenum method based on regression analysis of ascorbic acid, against regression equation $(y=196.4 x+0.179)$ and coefficient; $\mathrm{r}^{2}=0.990$ at a different concentration $(0.001$ to $0.005 \mu \mathrm{g} / \mathrm{ml})$. Reducing power of the plant extract increases linearly against regression equation $(\mathrm{y}=0.112 \mathrm{x}+0.121)$ and coefficient; $\mathrm{r}^{2}=0.985$ at a concentration ( 2 to $10 \mu \mathrm{g} / \mathrm{ml}$ ), like the standard. Estimation of free radical scavenging activity through DPPH assay is most widely used for screening of medicinal plants having anti oxidant activity. The mechanism involves the decolorization of solution through electron donated by anti oxidant moiety (standard/plant extract) and thus stabilizing the DPPH radical. The $\mathrm{IC}_{50}$ value for the in vitro DPPH assay was at $0.50 \mu \mathrm{g} / \mathrm{ml}$ against regression equation $(y=028252 x+35.65)$ and coefficient; $r^{2}=0.905$. The results clearly indicate the significant antioxidant activity in the plant which is in positive coorelation with the presence of phenolic acids and flavonoids which are known to impart antioxidant potential to the plant.

\section{Antidiabetic activity}

The antidiabetic activity of $H$. officinalis extract was determined by inhibition of biochemical activity of the alpha amylase enzyme. Starch iodine assay model systems involved. Inhibitory activity of the extract on $\alpha$-amylase was observed in the range $0.1-0.5 \mathrm{mg} / \mathrm{ml}$. The $\mathrm{IC}_{50}$ of the methnolic extract was found to be $0.8366 \mathrm{mg} / \mathrm{ml}$. However, the $\mathrm{IC}_{50}$ of the reference compound, acarbose, was found to be less than $0.025 \mathrm{mg} / \mathrm{ml}$ in the starch iodine color assay, respectively (Figure 5).

\section{DISCUSSION}

The results obtained suggest that caffeic acid being present in significant amount in the plant can act as a marker compound for the chemical identification of the plant and can be used to monitor the batch to batch consistency of the herbal product using this plant. H. officinalis has considerable antioxidant and antidiabetic activity. It can be used as a major cure for diseases resulting from damage caused by free radicals. Thus, the need for identifying and exploring the therapeutic potential of such useful medicinal plants is of very much significance to conserve our indigenous traditional knowledge and commercial formulation for market acceptability and competency.

\section{CONCLUSION}

In the present study physicochemical standardization parameters and phytochemical constituents identified will be helpful in the identification, standardization and quality control of this herbal drug.

\section{ACKNOWLEDGEMENT}

The authors are thankful to the Director of CSIR-NBRI for providing facilities and encouragement throughout the work.

\section{CONFLICT OF INTEREST}

There are no conflicts of interest.

\section{ABBREVIATIONS}

HPTLC: High-performance thin-layer chromatography; DPPH: 2,2-diphenyl-1-picrylhydrazyl; IC: Inhibitory concentration; API: Ayurvedic Pharmacopoeia of India.

\section{REFERENCES}

1. Chopra RN, Nayar SL, Chopra IC. Glossary of Indian medicinal plants. (NISCAIRCSIR, New Delhi). 2009;139.

2. Khazaie HR, Nadjafi F, Bannayan M. Effect of irrigation frequency and planting density on herbage biomass and oil production of thyme (Thymus vulgaris) and hyssop (Hyssopus officinalis). Ind Crops Prod. 2008;27(3):315-21.

3. Lawless J. The Encyclopedia of Essential Oils. Thorsons. 2002;110-11.

4. Kizil S, Toncer O, Ipek A, Arslan N, Saglam S, Khawar KM, et al. Blooming stages of Turkish hyssop (Hyssopus officinalis L.) affect essential oil composition. Acta Agriculturae Scandinavica. 2008;58(3):273-9

5. Kreis W, Kaplan MH, Freeman J, Sun DK, Sarin PS, et al. Inhibition of HIV replication by Hyssopus officinalis extracts. Antiviral Research. 1990;(14):323-37.

6. Gollapudi S, Sharma HA, Aggarwal S, Byers LD, Ensley HE, Gupta S, et al. Isolation of a previously unidentified polysaccharide (MAR-10) from Hyssopus officinalis that exhibits strong activity against human immunodeficiency virus type 1. Biochem. Biophysical Res Comm. 1995;210(1):145-51.

7. Fraternale D, Ricci D, Epifano F, Curini M. Composition and antifungal activity of two essential oils of hyssop (Hyssopus officinalis L.). J Essent Oil Res. 2004;16(6):617-22.

8. Kermanjani A, Jalalizadegan B, Tabatabaie F. Comparison of Hyssopus officinalis, Tussilage farfara, Carum copticum Extracts versus Systemic Glucantime in the Treatment of Cutaneous leishmaniasis in Balb/c Mice. Adv Std Biol. $2015 ; 7(2): 49-54$

9. Khodzhimotoy, Ramazanova Chalchat. Variability and biologically active component of Lamiaceae species. 2007.

10. Letessier MP, Svoboda KP, Walters DR. Antifungal activity of the essential oil of hyssop (Hyssopus officinalis). J Phytopathology. 2001;149(11-12):673-8.

11. Peach K, Tracy MV. Modern Methods of Plant Analysis. Heidelberg: Springer. 1955;3(4):258-61.

12. Anonymous, Indian Pharmacopoeia. Government of India, Ministry of Health and Family Welfare. New Delhi. 2007;191.

13. Anonymous, Ayurvedic pharmacopoeia of India. Government of India. 
Department of Health, Ministry of Health and Family Welfare. New Delhi. 2004;1(1):152-65.

14. Misra. BMC Res Notes 2015:8:324DOI 10.1186/s13104-015-1290-x.

15. Liyana-Pathiranan CM, Shahidi F. Antioxidant activity of commercial soft and hard wheat (Triticum aestivum) as affected by gastric $\mathrm{pH}$ conditions. Agric Food Chem. 2005;53(7):2433-40.

16. Kumaran A, Karunakaran RJ. In vitro, antioxidant activities of methanol extract of Phyllanthus species from India. Lebens-Wiss Technologie. 2007;40(2):344-52.

17. Prieto $P$, Pineda M, Aguilar M. Spectrophotometric quantitation of antioxidant capacity through the formation of a phosphomolybdenum complex: specific application to the determination of vitamin E. Anal Biochem. 1999;269(2):337-41.

18. Xiao Z, Storms R, Tsang A. A quantitative starch-iodine method for measuring alpha-amylase and glucoamylase activities. Anal Biochem. 2006;351(1):146-8.
GRAPHICAL ABSTRACT

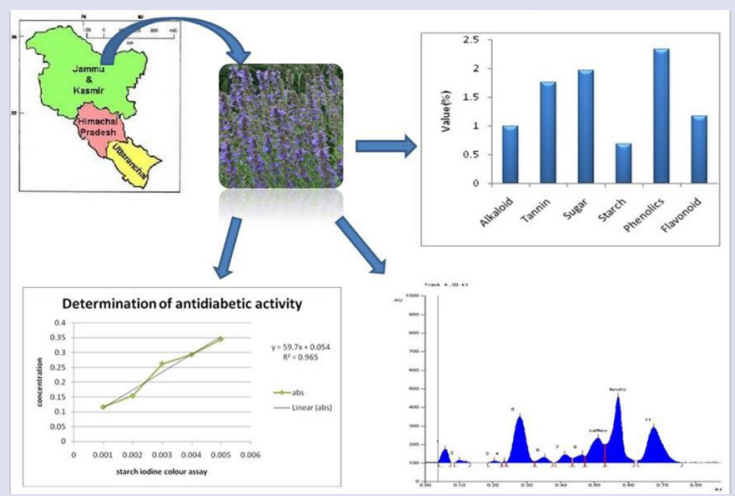

\section{SUMMARY}

- Physicochemical and phytochemical study was done to evaluate the quality standard of raw drug.

- The content of ferulic acid was found to be higher than caffeic acid.

- In vitro antidiabetic and antioxidant activity exhibit potential activity in targeted species.

- Evaluated pharmacognostical standards are useful for identification and authentication purposes.

Cite this article: Srivastava A, Awasthi K, Kumar B, Misra A, Srivastava S. Pharmacognostic and Pharmacological Evaluation of Hyssopus officinalis L. (Lamiaceae) Collected from Kashmir Himalayas, India. Pharmacog J. 2018;10(4):690-3. 